\title{
ATO ecodriving design to minimise energy consumption in Metro de Bilbao
}

\author{
A. P. Cucala ${ }^{1}$, A. Fernández ${ }^{1}$, M. Domínguez ${ }^{1}$, J. M. Ortega ${ }^{2}$, \\ L. Ramos ${ }^{2} \&$ A. Galarraga ${ }^{2}$ \\ ${ }^{1}$ Universidad Pontificia Comillas, Spain \\ ${ }^{2}$ Metro de Bilbao, Spain
}

\begin{abstract}
Different strategies are being applied nowadays to minimize energy consumption in Bilbao Underground (Metro de Bilbao). For that purpose, ATO driving commands in Metro de Bilbao have been optimized in order to reduce the consumption of traffic operation, taking into account operational requirements that are observed or even more improved. These operational requirements are the running time, comfort of passengers and minimum speed along track curves (due to rolling stock and track maintenance requirements).

First, new driving capabilities of the onboard ATO equipment have been proposed, for the execution of different speed regulation commands, which will allow finding new optimal solutions.

Second, a design method of optimal speed commands has been applied. For that purpose a detailed analysis of running times and consumption along all the lines in Metro de Bilbao has been developed, based on a detailed simulation tool. This simulator has been tuned by means of on board measurements of speed, traction force, consumption, etc. A specific efficiency model has been implemented. The resulting simulator has been validated comparing the measured train motion and the simulated one. Once the accuracy of the simulator as been validated, simulations of the train motion have been executed for the different values of the ATO equipment: acceleration, deceleration as well as the proposed modification to apply different speed regulations.

Finally, the optimal ATO speed commands have been designed and the associated expected energy savings are close to $8 \%$.

Keywords: energy consumption, speed commands design, train simulation, energy efficient driving, ATO, metro, eco-driving.
\end{abstract}




\section{Introduction}

Bilbao Underground (Metro de Bilbao) is involved in a strategic plan to reduce the energy consumption, by means of reversible substations, led lighting and at this moment the implementation of ecodriving.

The Railways Research Group of IIT (Universidad Pontificia Comillas) has been developing a research line focused on the optimisation of energy efficiency in railway operation, including ecodriving design, traffic regulation systems, design of efficient timetables, and the traction electrical network. Ecodriving models have been developed for high speed trains that have been tested on RENFE commercial services (20\% of energy savings were measured) [1, 2], as well as specific models for metro lines equipped with Automatic Train Operation systems (ATO) (where 13\% of average energy savings were measured) [3].

Trains equipped with ATO systems automatically execute the preprogrammed speed profile. For each interstation, a set of speed profiles are designed (usually 3 or 4) with different running times (and different associated energy consumption).

The centralized traffic regulation system decides in real time the speed command that has to be sent to each train at each interstation. If a train is delayed, the flat-out speed command will be sent to the train. The time difference between the flat-out and the nominal speed profile is the time margin available for recovery delays.

A slow speed profile command is sent when the train is too next to the preceding one, or when the headway with the following train is too large and has to be reduced. When a train has to be held, the traffic regulation system sends first a slow speed command, instead of increasing the dwell time at station, in order to reduce energy consumption.

Typically, the design of the ATO speed commands considers just the target running time as the design objective, observing the speed limits and comfort constraints. However, different speed profiles can be configured in the ATO equipment leading to the same running time, but with different energy consumption. The proposed optimal design includes also the energy efficiency as an objective of the design model, to minimize consumption for the required running time. Thus, as a result, the energy consumption is optimized without affecting the passengers' quality of service.

\section{State of the art: optimal design of ATO speed commands}

Mathematical models have been applied for the design of train ecodriving, based mainly on optimal control [4]. However, these models include simplifications on the train model and on the ATO equipment model. As a consequence, these results cannot be implemented on the real equipment in service, because these profiles cannot be programmed on the equipment and because high accuracy is required (time difference between the designed speed profiles in metro lines is just around 5 seconds). 
Thus, models based on detailed simulation are an appropriate alternative for the design of speed commands, where the model can be as accurate and realistic as necessary, as shown in [3] for ATO design and $[2,5]$ for the manual driving model. Combined with simulation, different optimization techniques have been applied: Genetic Algorithms (GA) [6], neural networks [7], etc. In these cases the optimal solution depends on the weighting factor used to balance running time and energy consumption.

The ATO model implemented has to consider the specific characteristic of the equipment. In metro ATO systems, speed profiles are programmed by means of control variables to be configured with discrete values. These control variables are: coast speed, remotoring speed, regulation constant speed, acceleration and deceleration rates. Associated to these variables and their possible discrete values, the solution space consists typically on around 250 possible alternative speed profiles per interstation. This fact allows an exhaustive simulation of every possible ATO profile, and then the application of decision theory techniques to select the set of solutions per interstation. This procedure and its application of a Metro de Madrid line have been described in [3].

In this paper the optimal design method is applied to Metro de Bilbao, taking into account the specific technical and operational constraints.

\section{Characteristics of Metro de Bilbao railway network}

Metro de Bilbao network is composed by 2 lines with a common section ("Y" shape) as shown in Figure 1, as well as the traction electrical substations and their characteristics.

Three different types of rolling stock are circulating in Metro de Bilbao network: UT500, UT550 and UT600 and their specific characteristics have to be taken into account during the design process of speed profiles.

Table 1 shows the lines and track characteristics of Metro de Bilbao network.

Table 1: $\quad$ Track characteristics.

\begin{tabular}{|l|c|c|}
\hline & Metro de Bilbao & \\
\hline & minimum & $407 \mathrm{~m}$ \\
\hline Interstation distances & maximum & $3.477 \mathrm{~m}$ \\
\hline & average & $1.110 \mathrm{~m}$ \\
\hline Maximum slope & $59,92 \%$ o & $189 \mathrm{~m}$ \\
\hline Maximum speed & $54,70 \% \mathrm{o}$ & $264 \mathrm{~m}$ \\
\hline
\end{tabular}




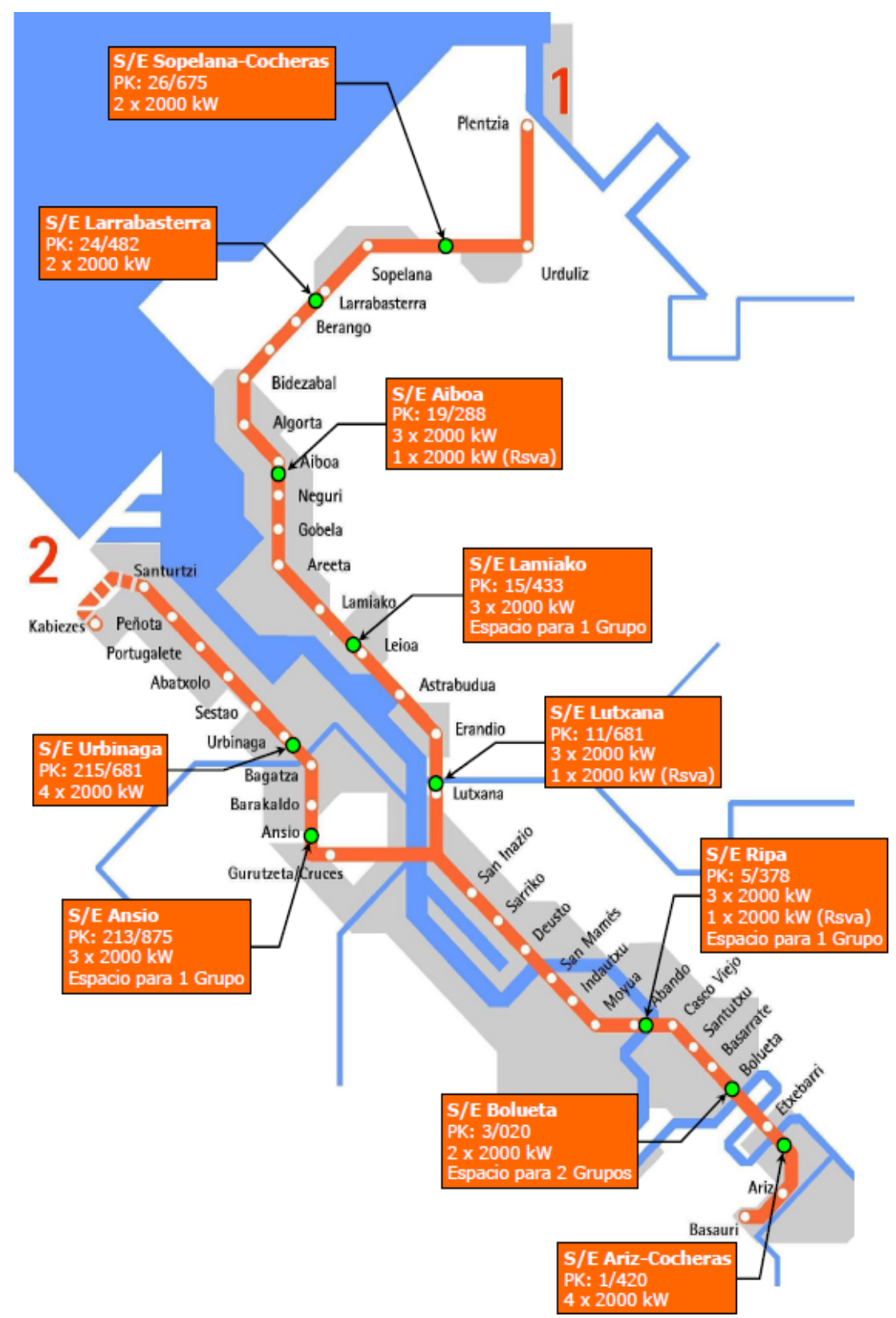

Figure 1: $\quad$ Metro de Bilbao railway network. 
The centralized traffic regulation system in Metro de Bilbao sends a regulation command to each train when it is at the station. This command corresponds to the fast $(\mathrm{F})$, nominal $(\mathrm{N})$ or slow $(\mathrm{S})$ speed profile, depending on the traffic situation at each moment. This command is sent through the track circuit at the station to the ATP antenna at the train, and the onboard equipment decodes the command $\mathrm{F}, \mathrm{N}$, or $\mathrm{S}$ into the corresponding values of acceleration and deceleration rates. The speed regulation command is sent to the train at each track circuit and its value is always the same, not depending on the ATO command being executed ( $\mathrm{F}, \mathrm{N}$ or $\mathrm{S}$ ).

In conclusion, nowadays it is possible to vary just the acceleration and deceleration rates in order to obtain different running times per interstation, but not the speed at each track circuit, that is the maximum one.

Another important constraint to be considered is the limitation imposed to the minimum speed required circulating along track curves, in order to avoid the track wear. This speed limitation is between 25 and $65 \mathrm{~km} / \mathrm{h}$, and it will constrain the design of ATO speed profiles.

\section{The train simulator}

The decision variables in the optimal design process are the running time and the energy consumption. As a consequence, it will be necessary a very accurate calculation of these two variables. Thus the train model has been modularized, as shown in Figure 2, in order to tune and validate each module independently of the rest, minimizing the simulation error of each module. Additionally, this structure permits the substitution of a specific module, for example, a different type of train equipped with the same ATO system.

Each module has been validated comparing the simulation results with measurements recorded onboard the train.

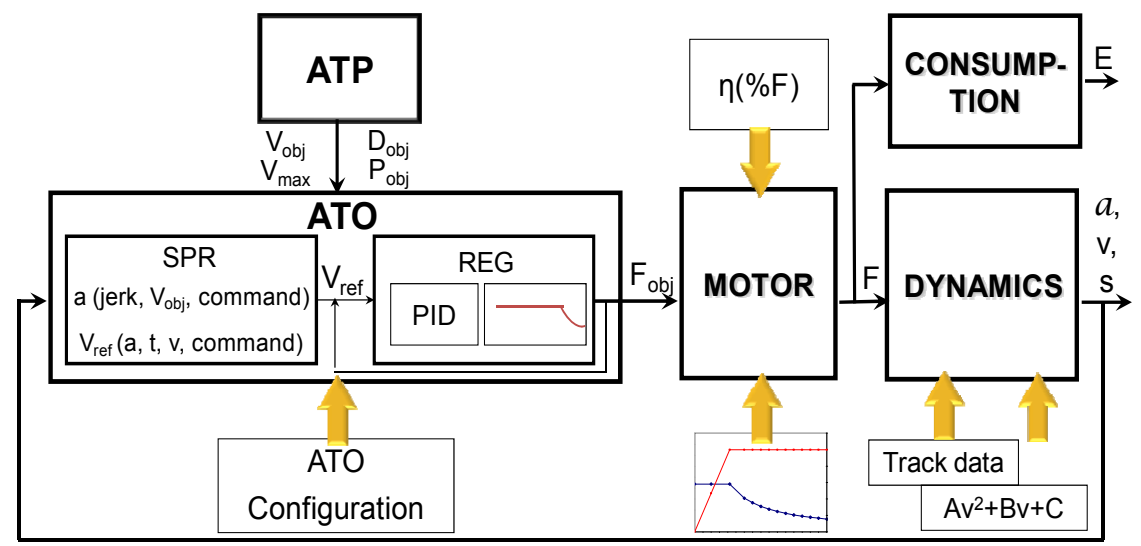

Figure 2: $\quad$ Structure of the train simulator. 
The ATO module (see Figure 2) sends an output to the motor module that is the traction force requested. Given the driving commands acceleration and deceleration rates and the speed regulation, and given the dynamic variables at each simulation instant, the traction force to be requested is calculated.

The Motor module simulates the behavior of the traction equipment, and given the command requested by the ATO, generates the traction or braking efforts.

The Dynamics module calculates the forces balance at each instant, taking into account the running resistances, track slopes and the traction/braking force of the motor. As a result, it calculates the acceleration rate as well as the speed and position of the train at the next simulation step.

Finally, the Consumption module calculates the mechanical work of the motor at each step that is divided by the efficiency coefficient of the traction equipment, providing the electrical power consumption measured at the pantograph. The integration of this power is the energy consumption associated to each speed profile simulated.

The following Figure 3 shows the comparison between simulation and onboard measurements at a specific interstation: speed, traction force, command calculated by the ATO and energy consumption.

In Figure 4 the energy efficiency model is shown as a function of the traction force percentage applied. This model has been tuned by means of onboard measurements for each type of train.

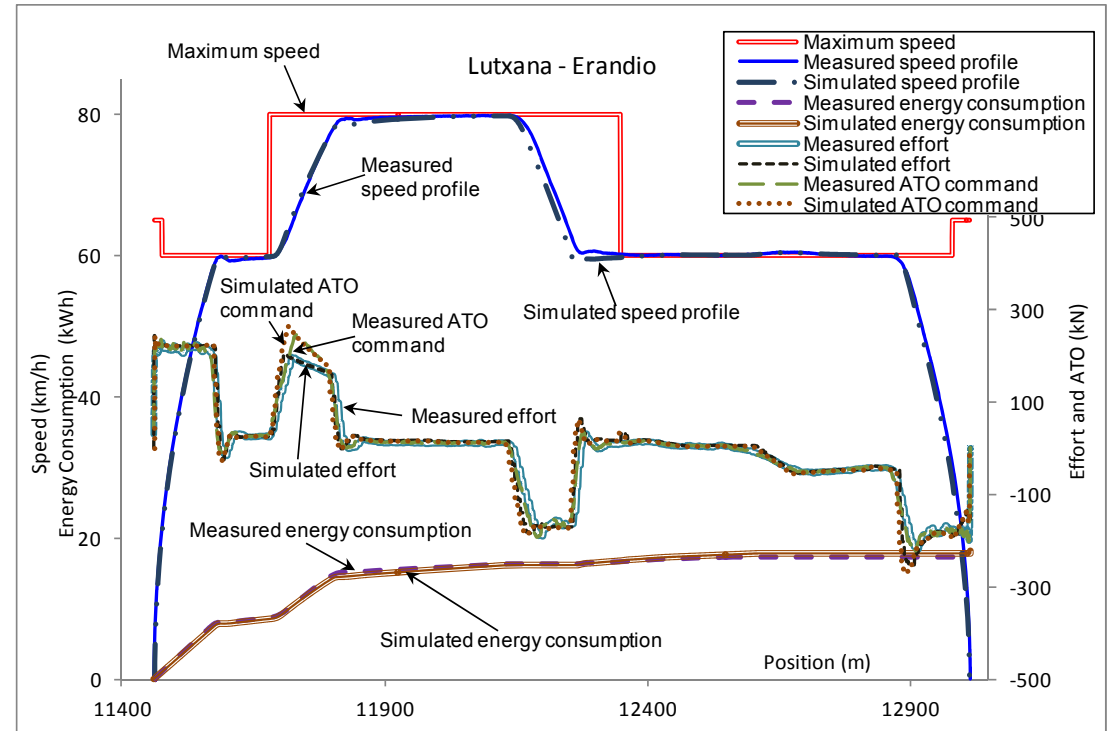

Figure 3: Interstation Lutxana-Erandio: comparison between simulation and onboard measurements. 


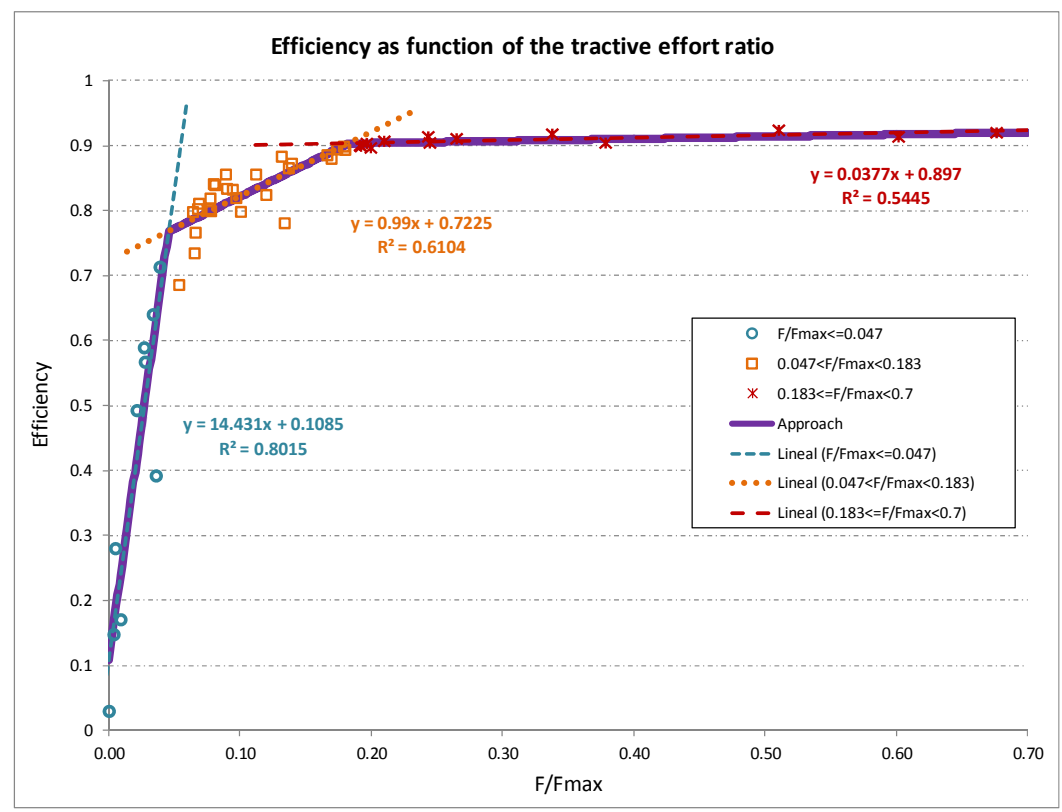

Figure 4: Energy efficiency of the motor as a function of the traction force percentage.

\section{The speed profiles design}

In the ATO speed profiles that are nowadays in service the acceleration and deceleration rate associated to the $F$ command is $1.2 \mathrm{~m} / \mathrm{s}^{2}$, that is the maximum permitted value. The $\mathrm{N}$ command has an acceleration and deceleration rate of $1 \mathrm{~m} / \mathrm{s}^{2}$. And the $\mathrm{S}$ command has an acceleration rate of $0.8 \mathrm{~m} / \mathrm{s}^{2}$ and deceleration rate of $0.6 \mathrm{~m} / \mathrm{s}^{2}$. After the study and evaluation of the energy efficiency coefficient model it can be concluded that as the efficiency of the traction equipment increases at high percentages of traction force, it is preferred to reduce running times increasing acceleration and deceleration rates and reducing the value of speed regulation. Additionally, this way the aerodynamic running resistance decreases, reducing the energy consumption.

In conclusion, the design strategy applied to design the $\mathrm{N}$ and $\mathrm{S}$ commands is to maintain the maximum acceleration and deceleration rates, and to reduce the speed to the value, necessary to obtain the $\mathrm{N}$ and $\mathrm{S}$ running times required by Metro de Bilbao.

This strategy implies a modification of the actual ATO system, and the software onboard the train has to be updated to apply a constant speed reduction each time an $\mathrm{N}$ command is received and another reduction every time an $\mathrm{S}$ command is received by the train. This means that the speed reduction cannot be calculated to be the optimal at each interstation, because it has to be the same along the whole network. Thus, the global optimum of the network has to be 
calculated. The speed reduction for $\mathrm{N}$ and $\mathrm{S}$ commands is designed making use of the detailed simulator previously described. The objective is that the newly designed nominal speed profiles provide similar running time between terminal stations as the published commercial time.

Speed reductions will be applied just to those track circuits with maximum speed over $60-65 \mathrm{~km} / \mathrm{h}$, to avoid too low speeds that could be below the speed constraint of curves.

\section{Results}

A software tool has been developed for the assisted design of ATO speed profiles, where the acceleration and deceleration rates can be configured, as well as the speed reductions to be analyzed. This tool integrates the train simulator that calculates the running times between terminal stations and the energy consumption.

The following table shows the simulation results comparing with the running time of the nominal speed profile nowadays in service as well as its energy consumption. The speed profiles simulated are those with maximum acceleration and deceleration rates, and different values of speed reductions. For each speed reduction, it is shown the total consumption (along the whole network), the associated energy savings, and the running time difference with respect to the commercial running time (along the whole network). For speed reductions over $7 \mathrm{~km} / \mathrm{h}$ energy savings would be expected. If the speed reduction is $20 \mathrm{~km} / \mathrm{h}$ the associated energy savings would be $9.44 \%$. This speed reduction would be applied just if the minimum speed limit along curves is observed $(60 \mathrm{~km} / \mathrm{h})$.

Table 2: $\quad$ Energy savings results and running time differences compared to the commercial service.

\begin{tabular}{|c|c|c|c|c|}
\hline $\begin{array}{c}\text { Speed } \\
\text { restriction } \\
\mathbf{( k m} / \mathbf{h})\end{array}$ & $\begin{array}{c}\text { Total energy } \\
\text { consumption } \\
\mathbf{( k W h )}\end{array}$ & $\begin{array}{c}\text { Total energy } \\
\mathbf{s a v i n g s} \\
\mathbf{( k W h}\end{array}$ & $\begin{array}{c}\text { Total energy } \\
\text { savings } \\
\mathbf{( \% )}\end{array}$ & $\begin{array}{c}\text { Total running time } \\
\mathbf{d i f f e r e n c e} \\
\mathbf{( s )}\end{array}$ \\
\hline 5 & 1303.12 & -13.74 & -1.07 & -313.60 \\
\hline 10 & 1245.55 & 43.82 & 3.42 & -236.90 \\
\hline 15 & 1201.27 & 88.10 & 6.87 & -158.30 \\
\hline 16 & 1194.31 & 95.07 & 7.41 & -146.50 \\
\hline 17 & 1188.12 & 101.26 & 7.89 & -136.55 \\
\hline 18 & 1181.06 & 108.31 & 8.44 & -126.00 \\
\hline 19 & 1174.05 & 115.32 & 8.99 & -113.05 \\
\hline 20 & 1168.21 & 121.17 & 9.44 & -102.30 \\
\hline
\end{tabular}

In consequence, the solution proposed is a speed profile applying $15 \mathrm{~km} / \mathrm{h}$ of speed reduction (new Normal profile), with an associated saving of $6,87 \%$, and another profile with $20 \mathrm{~km} / \mathrm{h}$ of speed reduction (new Slow profile with 9,44\% of energy savings). The optimal speed reduction has been calculated, valid for the entire railway network and for all the different types of trains circulating: UT500, UT550 and UT600. 


\section{Conclusions}

The design procedure of ATO speed profiles based on simulation has been applied to Metro de Bilbao ATO equipment, taking into account all the technical and operational constraints, as well and the different train characteristics. The resulting analysis provides expected energy savings around $8 \%$ of the total energy consumption measured at the pantograph. To implement the solution, a software modification of the onboard ATO equipment has been proposed in order to execute speed reductions below the maximum speed of each track circuit, with the maximum acceleration and deceleration rates.

When the train is delayed, the traffic regulation system sends a fast command, and no speed reduction is applied.

The modifications affect just to the onboard software and not to the track equipment nor to the centralized traffic regulation system.

\section{References}

[1] Sicre, C., Cucala, A. P., Fernández-Cardador, A., and Lukaszewicz, P., "Modelling and optimising energy efficient manual driving on High Speed Lines," IEEJ Transactions on Electrical and Electronic Engineering, (in press).

[2] Cucala, A.P., A. Fernández-Cardador, C. Sicre, M. Domínguez, "Fuzzy optimal schedule of high speed train operation to minimize energy consumption with uncertain delays and driver's behavioral response", Engineering Applications of Artificial Intelligence, (in press).

[3] Domínguez, M., Fernández, A., Cucala, A. P., and Lukaszewicz, P., "Optimal design of metro automatic train operation speed profiles for reducing energy consumption," Proceedings of the Institution of Mechanical Engineers, Part F: Journal of Rail and Rapid Transit, vol. 225, pp. 463-474, 2011.

[4] Khmelnitsky, E., "On an Optimal Control Problem of Train Operation," IEEE Transactions on Automatic Control, vol. 45, pp. 1257, 2000.

[5] Lukaszewicz, P., "Energy Consumption and Running Time for Trains," KTH, Department of Vehicle Engineering: Royal Institute of Technology, Stockholm, 2001, pp. 153.

[6] Bocharnikov, Y. V., Tobias, A. M., Roberts, C., Hillmansen, S., and Goodman, C. J., "Optimal driving strategy for traction energy saving on DC suburban railways," IET Electric Power Applications, vol. 1, pp. 675, 2007.

[7] Açikbas, S. and Söylemez, M. T., "Coasting point optimisation for mass rail transit lines using artificial neural networks and genetic algorithms," IET Electric Power Applications, vol. 2, pp. 172-182, 2008. 